\title{
Development of a Fruitlet Growth Model to Predict Thinner Response on Apples
}

\author{
Duane W. Greene ${ }^{1}$ \\ Stockbridge School of Agriculture, University of Massachusetts, Bowditch \\ Hall, Amherst, MA 01003
}

Alan N. Lakso and Terence L. Robinson
New York State Agricultural Experiments Station, Cornell University,
Geneva, NY 14456

Phillip Schwallier

Michigan State University, East Lansing, MI 48824

Additional index words. chemical thinning, fruit abscission, fruit growth, fruit set, Malus $\times$ domestica

\begin{abstract}
Previous reports have provided evidence that measuring fruit growth rate may be a viable method to predict if a fruit will abscise or persist through the June drop period. A series of experiments were carried out over several years to develop a procedure that could be used to predict the response to a chemical thinner application within 7 to 8 days after application and before thinners exhibit their final effect. The procedure developed involves tagging 105 spurs on seven individual trees distributed appropriately in the orchard. A minimum of two measurements must be made, one 3 to 4 days after application and again 7 to 8 days after application. This model requires that fruit measurement should not start before fruit grow to a diameter of $6 \mathrm{~mm}$ and individual fruit within a spur should be numbered and identified. The model is based on the assumption that if fruit growth rate of a particular fruit over the measurement period is less than $50 \%$ of the growth rate of the fastest growing fruit on the tree during the same growth period, it will abscise, whereas if fruit growth rate exceeds $50 \%$ of the growth rate of the fastest growing fruit, it will persist. All data can be entered into an Excel spreadsheet and the output in the summary page gives the predicted fruit set expressed as percentage of the total number of fruit present. The strategy for crop load adjustment with chemical thinners has evolved over the years to a point where most orchardists plan and are prepared to make two or more thinner applications. The dilemma associated with this approach is to determine if additional thinner applications are necessary. Up to this point a tool designed specifically to provide this information has not been developed.
\end{abstract}

Attempts have been made to identify factors that can be easily quantified and serve as early harbingers of ultimate fruit abscission. Ward and Marini (1999) applied a high rate of ethephon plus carbaryl to 'Golden Delicious' and 'Delicious' apples when fruit size was generally greater than $20 \mathrm{~mm}$. At intervals after application, they rated starch content, cellulose activity and quantified respiration rate, water potential, and growth rate. From this and other studies, they concluded that daily fruit measurement is the only practical method to assess early thinner response. Byers et al. (1991), Greene and Krupa (1999), and Wertheim (1971) have also pointed out the usefulness of measuring fruit growth to assess potential fruit drop after thinner application.

Several investigators have used measurement of fruit growth as the primary

Received for publication 29 Aug. 2012. Accepted for publication 14 Mar. 2013.

${ }^{1}$ To whom reprint requests should be addressed; e-mail dgreene@pssci.umass.edu. number of fruit clusters on several trees. To accomplish this, individual spurs are tagged and numbered consecutively from 1 up to the number to be placed on each tree or limb. Between petal fall and the time a thinner is applied, the numbered tags are placed on spurs throughout the tree canopy. All trees received a chemical thinning treatment commensurate with the cultivar and the predicted weather conditions. Just before thinner application, but not before fruit reach a size of $6 \mathrm{~mm}$, all fruit in the spur are numbered with an indelible marker and measured for diameter with a digital caliper. The data are recorded in a spreadsheet arranged by tree, spur, and then number in the spur. All fruit are measured the day of application and again at 2- to 3-d intervals after thinner application by placing the calipers on the location on the fruit where they were numbered. By placing the calipers on the same place on the fruit each time, the variability associated with measuring asymmetrically shaped fruit is substantially reduced. It is important that the growth of each fruit is identified and individually tracked in the spreadsheet. In the development process of this model, fruit diameter measurements were continued initially until fruit size of 20 to $25 \mathrm{~mm}$ was reached. At the end of the June drop period when fruits were at least $30 \mathrm{~mm}$ in diameter, final fruit set was determined so that the persisting fruit could be identified with the growth rate history of each fruit. After monitoring fruit growth on many spurs for 2 years, it became obvious that the fastest growing fruit were those that were most likely to persist.

In developing the final protocol of this thinning prediction tool, we conducted a number of experiments designed to help us determine the number of spurs to tag per tree, the location within the canopy or spurs to tag, which fruit would abscise, and which fruit would persist to harvest.

\section{Determining when to start to measure} fruit

'McIntosh/M7', 1998-99. In a block of response (Greene and Krupa, 1999. Green et al., 2005a. 2005b; Jankovic et al., 2009; Marini, 1998; McArtney and Obermiller, 2010; Ward and Marini, 1999). The premise on which our predictive model is based is the observation that fruit that are destined to drop will slow and stop growth well in advance of the actual time of abscission. This reduced fruit occurs soon after thinner application and usually well within the window to make another application if needed. The objective of these investigations was to develop an easy-to-use system that could be used by orchardists to assess the effectiveness of previously applied thinner(s). This article chronicles a number of experiments that were done over several years to establish important details necessary for accurate prediction.

\section{Materials and Methods}

\section{Generalized method}

This fruit thinning prediction tool requires the measurement of fruit growth over a several day period of each fruit on a certain 30-year-old 'McIntosh/M.7', six uniform trees were selected. Twenty well-exposed spurs were identified. Ten spurs were randomly selected to be open-pollinated spurs and the remaining 10 spurs were designated to prevent pollination. Just before the opening of the king flower, the spurs designated for pollen exclusion were covered with a $20 \mathrm{~cm} \times$ $20-\mathrm{cm}$ piece of Super Light Insect Barrier (Gardens Alive, Lawrenceburg, IN) and then the fabric barrier was secured to the spur base with a plastic tie. This barrier allowed light penetration and prevented bee visitation. A cluster of bee hives was placed $\approx 35 \mathrm{~m}$ from the trees. The day after petal fall (8 May 1998; 14 May 1999), the fabric insect barrier was removed from each spur and all fruit on all tagged spurs were individually marked, measured with a caliper, and then recorded. Fruit were measured again $3,5,7,10$, and $12 \mathrm{~d}$ after petal fall.

\section{Determine number of spurs to tag}

'Honeycrisp'/M.9. In 2005, five 6-yearold 'Honeycrisp' trees were selected. At the 
pink stage of flower development, every other flowering spur was tagged on each tree. In July, fruit set was recorded for every spur on the tree. There was an average of $\approx 350$ flowering spurs on these trees. Fruit set was then calculated by counting the number of fruit on every spur, every other spur, every fourth spur, every sixth spur, etc., out to one in every 30 spurs. The predicted set was calculated based on the actual number of fruit that was counted on the tree at the end of June drop. A figure of $\pm 10 \%$ accuracy was considered acceptable prediction precision. This experiment was again repeated in 2006 using the same criteria. The number of flowering spurs on these trees again averaged $\approx 350$.

'Autumn Rose Fuji'. In 2005, five 5-yearold 'Autumn Rose Fuji'/M.9 trained as a tall spindle tree were selected. Every other flowering spur on each tree was tagged. Fruit set was measured on each spur at the end of June drop in July. Predicted set was calculated similar to the method described for 'Honeycrisp'. This experiment was repeated on similar trees in 2006.

\section{Location of the spurs to tag}

'Honeycrisp'/M.9. In 2005, five trees were selected in a block of 6-year-old 'Honeycrisp' that were trained to a slender spindle training system. Three limb portions on the lower whorl of scaffolds and three in the midsection of the trees were selected, tagged, and the circumference taken. The central leader was also tagged and measured. Limb diameter of these limbs and the tagged portion of the central leader averaged between 7 and $10 \mathrm{~cm}$ limb circumference. At the pink stage of flower development, all blossom clusters on all tagged limbs were counted and the number recorded. Trees received a petal fall spray of $600 \mathrm{mg} \cdot \mathrm{L}^{-1}$ carbaryl (Sevin 80W; Bayer CropScience, Research Triangle Park, NC) and a $10-\mathrm{mm}$ spray of $5 \mathrm{mg} \cdot \mathrm{L}^{-1}$ 1-naphthaleneacetic acid (NAA) (Fruitone-N; AMVAC, Newport Beach, CA) as the thinning treatments. These were applied as dilute hand gun applications to the drip point. At the end of June drop, all persisting fruit on the tagged portion of the limbs were counted and fruit set calculated.

'Desert Rose Fuji'. In 2005, five 6-yearold trees trained as a tall spindle were selected. These trees were divided into four equal portions: top, the two middle sections, and the bottom. Flagging tape delineated the four sections on each tree. At the pink stage of flower development, all blossom clusters were counted on the trees and the number of flower clusters in each section was recorded. A dilute thinning spray containing $75 \mathrm{mg} \cdot \mathrm{L}^{-1}$ benzyladenine $\left(\mathrm{MaxCel}^{\circledR}\right.$, Valent BioSciences, Libertyville, IL) plus $600 \mathrm{mg} \cdot \mathrm{L}^{-1}$ carbaryl was applied to the drip point at the $10-\mathrm{mm}$ stage of fruit development using a hand gun. Final fruit set was measured on these trees at the end of June drop in July.

\section{Determining the growth rate of fruit that would abscise}

'Ace Spur Delicious'/M.26 and 'Golden Delicious'/M.7. Seven mature 'Delicious'/
M.26 trees and six mature 'Golden Delicious'/M.7 trees were selected and 15 spurs were tagged on each tree at petal fall. Just before thinner application, all fruit on each tagged spur were individually numbered and then their diameter measured and recorded. $\mathrm{NAA}$ at $7.5 \mathrm{mg} \cdot \mathrm{L}^{-1}$ plus $900 \mathrm{mg} \cdot \mathrm{L}^{-1}$ carbaryl was then applied. Fruit diameter of tagged fruit was measured again at $3 \mathrm{~d}$ and $7 \mathrm{~d}$ after thinner application. Final set was measured at the end of June drop. The growth rate of each fruit between Day 3 and Day 7 after application was calculated. The three fastest growing fruit on each tree were identified and designated as a growth rate of $100 \%$. The growth rate of all of the measured fruit on that tree was compared with the fastest growing fruit and assigned a percent growth rate of the fastest growing fruit. The fruit were separated into 10 growth categories: $0 \%$ to $9 \%, 10 \%$ to $19 \%, 20 \%$ to $29 \%, \ldots 91 \%$ to $100 \%$ of the fastest growing. Within each growth category, the percentage of fruit that abscised and the percentage that continued to grow were calculated.

\section{Determination of the time after thinner application when an accurate prediction could be made}

We compiled a list of 13 chemical thinning experiments with seven cultivars that were done over a 4-year period where we had repeated fruit measurements of persisting fruit from soon after petal fall until $25-\mathrm{mm}$ fruit size. Using the final set determined after June drop on the tagged spurs, we determined how many days it required after application for us to make a prediction with at least $90 \%$ accuracy. We then determined the growing degree-days (GDD) (base $4{ }^{\circ} \mathrm{C}$ ) that had accumulated from the time of application until the date that we could make this prediction. The GDD were calculated using GDD = (maximum temperature ${ }^{\circ} \mathrm{C}+$ minimum temperature $\left.{ }^{\circ} \mathrm{C} / 2\right)-4.4{ }^{\circ} \mathrm{C}$.

\section{Construction of an Excel spreadsheet}

To facilitate the large number of calculations that were necessary to calculate individual fruit growth rate and predict which would abscise and which would persist, we constructed an Excel spreadsheet (Microsoft Inc., Redmond, WA) with macro programs embedded where all data could be cut and pasted into the sheet and then with minimal additional work, the final predicted fruit set could be calculated. The spreadsheet would calculate growth rate and indicate percentage fruit set.

\section{Results and Discussion}

The basis for the model. Our repeated measurements of fruit diameter in several experiments showed that the diameter growth rate of a fruit that will persist to harvest is steady and generally linear over the period from the time it reaches $\approx 7 \mathrm{~mm}$ diameter until it grows to 20 to $25 \mathrm{~mm}$ in diameter (Fig. 1). Fruit that are destined to abscise as a result of thinner application or some other reason such as carbohydrate stress or from some other environmental stress may slow growth as early as $2 \mathrm{~d}$ after application but generally it requires 3 to $4 \mathrm{~d}$ for this to happen. By $7 \mathrm{~d}$ after thinner application, the reduction in growth rate is much more apparent and it is this reduction in growth rate of abscising fruit, compared with the growth rate of fruit that will persist to harvest, that forms the basis for this predictive model.

When to start to measure fruit. Flowers that are not pollinated do not increase in size, although they persist for a number of days after bloom (Fig. 2). The receptacle of flowers is slow to increase in size. For the first $5 \mathrm{~d}$ after petal fall, growth of these pollinated flowers is quite slow, and unless measurements are made during this period of time, it is difficult to differentiate between pollinated and unpollinated flowers. After $7 \mathrm{~d}$, growth of pollinated flowers accelerates and enters a log phase of growth, whereas unpollinated flowers do not grow. Therefore, we recommend that the start of fruit measurement should be delayed until the fruit reach 6 in diameter or soon after, because this is the first time that the growth rate of the two types of fruit can be separated.

Number of spurs to tag and measure. Tagging, marking, and measuring spurs are time-consuming processes. Consequently, we wanted to determine the minimum number

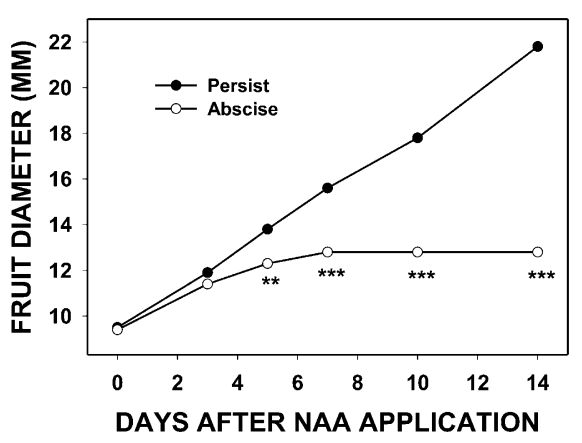

Fig. 1. Mean growth in fruit diameter over a 14-d period of a fruit that will persist to harvest and one that was induced to drop after thinner application. The $* *$ and $* * *$ indicate statistical significance between persisting and abscising fruit at $P=0.01$ and 0.001 , respectively.

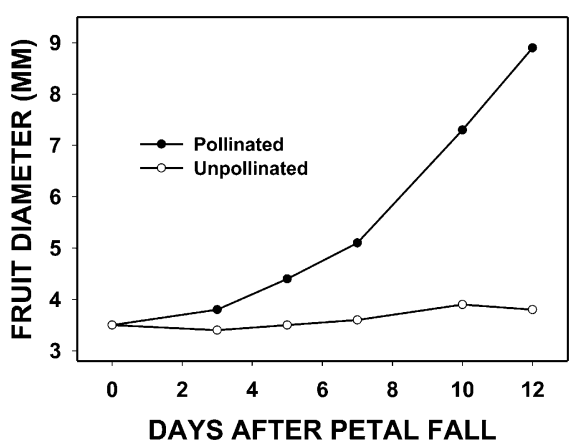

Fig. 2. Fruit diameter change over a $12-\mathrm{d}$ period after petal fall of 'McIntosh' apple fruitlets that were either pollinated or prevented from being pollinated. The $*$ and $* *$ indicate statistical significance at $P=0.05$ and 0.01 , respectively. 
of spurs to measure to get a good prediction of the thinning response on the tree without incurring unnecessary work. Results in Table 1 show how close predicted set was to actual set when varying numbers of spurs were counted ranging from every other spur to one in 30 spurs. A $100 \%$ prediction is one in which the predicted fruit set is the same as the final fruit set actually counted on the tree or branch at the end of June drop. A 90\% or $110 \%$ prediction represents a prediction that is either $10 \%$ below or $10 \%$ above the final set, respectively. In our estimation, a sampling error of $\pm 10 \%$ was an acceptably accurate prediction. When the estimated fruit set is averaged over both cultivars and 2 years, the accuracy of the prediction ranged from $96 \%$ to $108 \%$ (data not shown). However, as the ratio between measured and not measured fruit increased, the variability in the prediction also increased (Table 1). Therefore, in our judgment, measuring 15 spurs per tree on seven trees (a total of 105 spurs) represents a good compromise between accuracy of prediction and having a number of fruit that is manageable to measure.

Location of the spurs to tag. In our studies, bloom and fruit set were measured on relatively young 'Honeycrisp' trees. The distribution of bloom from the central leader to the upper and lower scaffold branches was similar (Table 2). However, greater fruit set occurred on the upper part of the central leader compared with the lower scaffold branches. On the tall spindle 'Fuji' trees, bloom was equally distributed in all sections of the tree but when final set was taken, there was a highly significant linear increase in fruit set from the lower portion to the upper portion of the tree (Table 3). Although bloom may appear uniformly distributed within the tree, it is apparent that the propensity to set differs with location. Selected spurs should be distributed on the tree in a way that represents the distribution of flowering spurs on that tree.

Determining the growth rate of fruit that would abscise. The relationship between rate of fruit growth between 4 and $7 \mathrm{~d}$ after thinner application (as a percentage of the rate of the fastest growing fruit) and final fruit abscission was roughly a sigmoid curve with those fruit with the lowest growth rate having the highest fruit abscission and those fruit with the highest growth rate having the lowest abscission (Fig. 3). We divided the continuum of fruit growth rate into three distinct groups or classes of fruit (Fig. 3). One group of fruit with growth rates of zero up to $\approx 40 \%$ of the fastest growing fruit set no fruit. Another group of fruit with growth rates of from $70 \%$ up to $100 \%$ of the fastest growing fruit had between a $90 \%$ to $96 \%$ chance of setting and persisting through June drop. McArtney and Obermiller (2010) also reported that a small percentage of the fastest growing fruit did abscise, but the reason for this lack of set was not apparent. A third group of fruit, which had growth rates between $40 \%$ and $60 \%$ of the fastest growing fruit, had variable fruit set. It appears that fruit with growth rates within this range may be most vulnerable to the application of chemical thinners and the exact shape of this curve may be modified by a number of factors including thinner used, weather conditions after application, vigor of the spur, and similar factors known to influence abscission. Based on this roughly sigmoidal curve, we selected a simplified two-phase curve with the inflection point at a growth rate of $50 \%$ to use in our model (Fig. 4). In our model, fruit with a growth rate of $50 \%$ or greater of the fastest growing fruit are predicted to persist, whereas those with a growth rate of less than $50 \%$ the growth rate of the fastest growing fruit are predicted to abscise.

When is the earliest that a reliable thinning prediction can be made? In developing the protocol for this thinning prediction tool, we noted that under most circumstances, a prediction of thinner efficacy could be made within 7 or $8 \mathrm{~d}$ of application. Some years we could not make this determination early, and in general, these instances were associated with periods of low temperature after application. Using the compiled list of 13 experiments (Table 4), a prediction of final fruit set with $90 \%$ accuracy could be made between 4 and $12 \mathrm{~d}$ after application. Based on the GDD, it appears that 100 to 130 GDD (base $4.4^{\circ} \mathrm{C}$ ) must be accumulated from the time of application to the time of prediction. For the majority of trials, 7 to $8 \mathrm{~d}$ was an appropriate time between the time of application and being able to make an accurate prediction. Although these data are useful and they do provide somewhat rough guidelines, greater precision in determining the time to make the final measurement is desirable.

Information based on both temperature and solar radiation appears to provide a more precise prediction of the thinning response (Lakso et al., 2006). The results from this MaluSim carbon balance model may aid in determining when an accurate prediction can be made. We suggest that running the model for the first $4 \mathrm{~d}$ after thinner application using actual weather data coupled with fruit growth measurements should provide improved precision when determining more accurately when a prediction can be made. Because actual rather than predicted data will be used, a high degree of precision should be achieved.

Another thinning prediction model that is being developed is based on estimating tree carbohydrate status to predict thinning response (Robinson and Lakso, 2011). This model uses both temperature and solar radiation inputs, both of which are important in predicting stress that fruit will be exposed to. This model is most useful to predict possible thinner response before thinner application. The model is being tested in New York, Michigan, North Carolina, Pennsylvania, New Jersey, and Massachusetts. The carbohydrate model is most useful to predict possible thinner efficacy before thinner application, whereas our fruit growth model is a proposed tool to be used after has been applied.
Table 1. Estimated fruit set as affected by the number of fruit samples. ${ }^{2}$

\begin{tabular}{lrrrrr}
\hline & \multicolumn{2}{c}{$\begin{array}{c}\text { Honeycrisp } \\
\text { Spurs }\end{array}$} & & \multicolumn{2}{c}{$\begin{array}{c}\text { Autumn } \\
\text { Rose Fuji (\%) }\end{array}$} \\
\cline { 2 - 3 } \cline { 5 - 6 } sampled & 2005 & 2006 & & 2005 & 2006 \\
\hline All spurs & 100 & 100 & & 100 & 100 \\
1 of 2 & 111 & 106 & & 100 & 94 \\
1 of 4 & 107 & 101 & & 107 & 94 \\
1 of 6 & 102 & 100 & & 97 & 88 \\
1 of 8 & 109 & 107 & & 95 & 100 \\
1 of 10 & 112 & 88 & & 101 & 84 \\
1 of 12 & 94 & 108 & & 130 & 103 \\
1 of 14 & 119 & 95 & & 85 & 96 \\
1 of 16 & 121 & 121 & & 91 & 83 \\
1 of 18 & 91 & 100 & & 93 & 117 \\
1 of 20 & 103 & 86 & & 134 & - \\
1 of 22 & 96 & 114 & & - \\
1 of 24 & 68 & 106 & 138 & - \\
1 of 30 & 131 & 83 & - & - \\
\hline
\end{tabular}

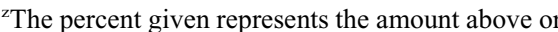
below the actual number of fruit counted on the tree at the end of June drop.

Table 2. Effect of limb location on flowering and fruit set of 'Honeycrisp'/M.9.

\begin{tabular}{lcr}
\hline & $\begin{array}{c}\text { Blossom clusters } \\
\text { per cm limb }\end{array}$ & $\begin{array}{c}\text { Fruit }^{\mathrm{z}} \\
\text { set }\end{array}$ \\
\cline { 2 - 3 } Limb location & x-section area & $(\%)$ \\
\hline $\begin{array}{c}\text { Low tier-scaffold } \\
\text { branch }\end{array}$ & $12.7 \mathrm{a}$ & $32 \mathrm{~b}$ \\
$\begin{array}{c}\text { Upper tier-scaffold } \\
\text { branches }\end{array}$ & $13.9 \mathrm{a}$ & $42 \mathrm{ab}$ \\
Central leader & $11.9 \mathrm{a}$ & $47 \mathrm{a}$ \\
\hline
\end{tabular}

${ }^{\text {z} M e a n ~ s e p a r a t i o n ~ D u n c a n ' s ~ m u l t i p l e ~ r a n g e ~ t e s t, ~} P=$ 0.05 .

Table 3. Influence of location in the canopy on flower bud present and fruit set on 'Desert Rose Fuji' apples trained as a tall spindle tree.

\begin{tabular}{lcr}
\hline & $\begin{array}{c}\text { Flowering } \\
\text { spurs }^{\mathrm{z}}\end{array}$ & $\begin{array}{c}\text { Fruit } \\
\text { set }\end{array}$ \\
\cline { 2 - 3 } (\% of total on \\
Location on tree & $\begin{array}{c}\text { the tree) } \\
(\%)\end{array}$ \\
\hline Lower portion 0-0.25 & 23.5 & 43 \\
Lower middle 0.25-0.50 & 27.1 & 69 \\
Upper middle 0.50-0.75 & 25.9 & 84 \\
Top of tree 0.75-1.0 & 23.5 & 110 \\
Significance & NS $^{\mathrm{z}}$ & $1^{* * *}$ \\
\hline
\end{tabular}

${ }_{\mathrm{NSS}}, * * *$ Nonsignificant or significant at $P=0.001 .1$ signifies a linear response.

GROWTH RATE INFLUENCES ABSCISSION

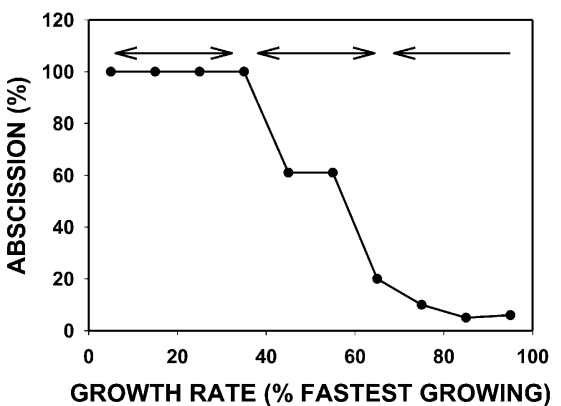

Fig. 3. Influence of growth rate of fruit compared with the fastest growing fruit and percentage of these fruit in the various categories that persist through June drop. Fruit measurements were made between 4 and $7 \mathrm{~d}$ after 1-naphthaleneacetic acid (NAA) plus carbaryl application on 'Delicious' and 'Golden Delicious' apples. 
How to use the fruit growth model. Using this fruit growth model will require a different approach to thinning than growers are normally accustomed to doing. We suggest that orchardists should have an end goal (fruit set target) in mind before starting the thinning process. This entails first calculating the

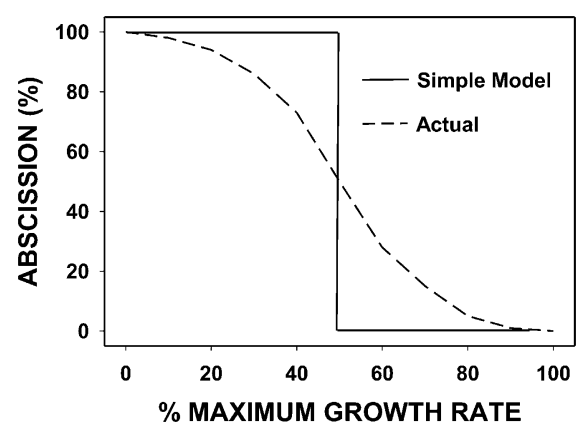

Fig. 4. Assumed curve illustrating fruit drop as influenced by growth rate and the fruit set used in the simple model to predict if a fruit persists or abscises. number of fruit that a grower would like to

harvest from that tree based on the tree planting density and desired yield. Second, the grower should determine the percentage of the flowers that should set and produce fruit to obtain the desired fruit number per tree. On tall spindle, superspindle, or other small-statured trees, we suggest counting the total number of blossom clusters on the whole tree. With larger statured trees, we suggest selecting two limbs per tree that are representative of the bloom density on that tree and in the orchard and counting the number of blossom clusters on these limbs and then establishing the desired number of fruit to harvest from these limbs/trees at the end of the season. For example, if for an orchard that has an average 200 blossom clusters per tree, you determined that you would like to have 100 fruit/tree at harvest, then one fruit set for each two blossom clusters should be the desired final set. Given that with the fruit growth model we suggest tagging 105 flowering spurs (15 spurs on seven trees), in this example, the target final number of persisting fruits would be between 52 and 53 fruit per tree. If on these 105 spurs we have 430 developing fruit, then we would

Table 4. Cumulative growing degree-days (base $4.4^{\circ} \mathrm{C}$ ) after application of thinners in $2003-06 .^{\mathrm{z}}$

\begin{tabular}{|c|c|c|c|c|c|c|c|c|}
\hline \multirow{4}{*}{$\begin{array}{l}\text { Days after } \\
\text { application }\end{array}$} & \multirow{2}{*}{\multicolumn{2}{|c|}{2003}} & \multirow{2}{*}{\multicolumn{2}{|c|}{2004}} & \multirow{2}{*}{\multicolumn{3}{|c|}{2005}} & \multirow{3}{*}{$\begin{array}{c}2006 \\
\text { Fuji } \\
\text { Braeburn }\end{array}$} \\
\hline & & & & & & & & \\
\hline & Delicious & Golden & Golden & Delicious & Braeburn & Delicious & Braeburn & \\
\hline & McIntosh & $\overline{\text { Delicious }}$ & Delicious & McIntosh & Fuji & & & Gala \\
\hline 1 & 14.3 & 22.8 & 9.2 & 10.3 & 7.9 & 10.0 & 12.8 & 28.3 \\
\hline 2 & 31.6 & 38.6 & 19.5 & 25.4 & 18.4 & 22.8 & 34.0 & 50.0 \\
\hline 3 & 46.4 & 56.0 & 30.3 & 29.0 & 28.4 & 44.0 & 58.6 & 84.1 \\
\hline 4 & 60.1 & 74.2 & 45.2 & 40.5 & 41.2 & 68.6 & 76.1 & $110.8^{*}, *$ \\
\hline 5 & 82.9 & 97.9 & 55.9 & 47.8 & 87.0 & 86.1 & 100.1 & $132.0^{*}$ \\
\hline 6 & 98.7 & 119.6 & 70.3 & 57.0 & 104.5 & 110.6 & 126.1 & 144.1 \\
\hline 7 & $116.1 *$ & $145.7^{*}$ & 84.8 & 67.3 & $129.0 *$ & $136.1^{*}$ & $151.4 *$ & 156.8 \\
\hline 8 & 134.3 & 161.7 & 84.8 & 78.1 & $154.5^{*}$ & 161.4 & 174.3 & 172.4 \\
\hline 9 & $158.0 *$ & 181.8 & 98.7 & 93.0 & 179.8 & 184.3 & 199.6 & 193.8 \\
\hline 10 & 179.7 & 207.3 & 110.2 & 103.7 & 202.7 & 209.6 & 223.4 & 206.3 \\
\hline 11 & 205.8 & 224.3 & 120.4 & $118.1^{*} *$ & 228.0 & 233.4 & 250.6 & 219.8 \\
\hline 12 & 221.3 & 240.9 & $132.9 *$ & 132.6 & 251.8 & 260.6 & 275.7 & 237.3 \\
\hline
\end{tabular}

${ }^{\mathrm{z}}$ The asterisk indicates the time after application that a prediction of final set could be made with at least a $90 \%$ accuracy.

Table 5. Suggested format to organize data into before entering into the Excel spreadsheet.

\begin{tabular}{lcccrr}
\hline & \multicolumn{5}{c}{ Predicting thinning Braeburn 2011 data } \\
\hline Repetitions & Spur & Fruit & 25 May 2011 & 29 May 2011 & 1 June 2011 \\
\hline 1 & 1 & 1 & 7.5 & 11.3 & 13.4 \\
1 & 1 & 2 & 6.1 & 6.6 & 6.8 \\
1 & 1 & 3 & 6.8 & 7.0 & 7.4 \\
1 & 1 & 4 & 6.4 & 9.6 & 9.3 \\
1 & 1 & 5 & 6.5 & 12.9 & 13.4 \\
1 & 2 & 1 & 10.5 & 7.9 & 7.9 \\
1 & 2 & 2 & 8.0 & 10.2 & 10.4 \\
1 & 2 & 3 & 8.6 & 6.4 & 6.5 \\
1 & 2 & 4 & 6.4 & 11.0 & 11.1 \\
1 & 2 & 5 & 3.8 & 9.0 & 9.1 \\
1 & 3 & 1 & 8.7 & 7.0 & 7.2 \\
1 & 3 & 2 & 7.1 & & 7.0 \\
1 & 3 & 3 & 7.0 & & 7.6 \\
1 & 3 & 4 & 4.1 & 10.8 & 5.8 \\
1 & 3 & 5 & 3.8 & 7.2 & 5.6 \\
1
\end{tabular}

want to have $12.2 \%$ of these developing fruits to persist to harvest. The output that the Excel spreadsheet provides is the predicted final set of the fruit on the tagged spurs. If spurs are appropriately selected throughout the canopy, this will be the predicted set for the orchard. When using the model if a grower finds that after his first chemical thinning spray, the predicted fruit set is higher than that which was decided on at the beginning of the thinning season, then additional thinning sprays should be considered.

The Excel spreadsheet model. The fruit growth model is located in two places on the web: <http://www.umass.fruitadvisor/2008/ predictfruitset2008.xls $>$ and <http://www. apples.msu.edu>.

A complete set of directions for the set-up and use of the model may be found at and downloaded from: <http:///www.umass.edu/ fruitadvisor/2008/predictthinprocedure.pdf $>$.

The model instructions for use are short and easy to follow. Data can be entered directly into the model or they can be imported by cutting and pasting (Table 5). The model makes all calculations. On the summary page, there are several outputs, but the most important one is found in the next to last column under the heading "Set based on original number of fruit." In the example provided previously, if the figure is $12.2 \%$, then thinning is completed for the year.

\section{Literature Cited}

Byers, R.E., D.H. Harbaugh, C.N. Presley, and T.K. Wolf. 1991. The influence of light on apple fruit abscission. J. Hort. Sci. 66:7-17.

Greene, D.W. and J. Krupa. 1999. Predicting fruit set and thinner response on apples. Proc. Mass. Fruit Growers' Assoc. 105:24-28.

Greene, D.W., J. Krupa, and M. Vezina. 2005a. A method to predict chemical thinner response on apples. Fruit Notes 70:12-17.

Greene, D.W., A.N. Lakso, and T.L. Robinson. 2005b. Predicting chemical thinner response on apple. Compact Fruit Tree 38(3):17-20.

Jankovic, D., J. Jankovic, and R. Blagojevic. 2009. Growth rate of apple fruit as a method of predicting their abscission. Acta Agr. Serbica Vol X1V 14(28):23-30.

Lakso, A.N., T.L. Robinson, and D.W. Greene 2006. Integration of environment, physiology, and fruit abscission via carbon balance modeling - Implications for understanding growth regulator response. Acta Hort. 727:321-326.

Marini, R.P. 1998. Predicting and assessing effectiveness of apple thinning treatments. Proc. Mass. Fruit Growers' Assoc. 104:28-31.

McArtney, S.J. and J.D. Obermiller. 2010. Evaluation of a model to predict the response of Gala apples to chemical thinners. Acta Hort. 884:581-585.

Robinson, T.L. and A.N. Lakso. 2011. Predicting chemical thinner response with a carbohydrate model. Acta Hort. 903:743-750.

Ward, D. and R.P. Marini. 1999. Growth and development of young apple fruit following applications of ethephon plus carbaryl for thinning. HortScience 34:1057-1059.

Wertheim, S.J. 1971. The drop of flowers and fruit in apples, with special reference to the June drop of Cox's Orange and its control with growth regulators. Meded. Landbouweschool, Wageningen, The Netherlands. 71-17. 